\title{
Clumped isotope signatures of abiotic methane formed via Fischer- Tropsch catalysis and their implications
}

NAIZHONG ZHANG ${ }^{1, *}$, YASUHITO SEKINE ${ }^{1}$, MAYUKO $^{2}$

NAKAGAWA $^{1}$ AND NAOHIRO YOSHIDA ${ }^{1}$

${ }^{1}$ Earth-Life Science Institute, Tokyo Institute of Technology, Tokyo, Japan (*correspondence: zhang@elsi.jp)

The clumped isotope of $\mathrm{CH}_{4}$ refers to isotopologues substituted by two or more rare stable isotopes, e.g. ${ }^{13} \mathrm{CH}_{3} \mathrm{D}$ and ${ }^{12} \mathrm{CH}_{2} \mathrm{D}_{2}$, whose abundance relative to a random distribution is temperature dependent (Stolper et al., 2014). Previous studies mainly focused on the microbial and thermogenic $\mathrm{CH}_{4}$ samples, while limited abiotic data has been reported by Young et al. (2017) and Wang et al. (2018) only. Two preliminary results of low-temperature Fischer-Tropsch Type (FTT) reaction (Sabatier reaction) using ruthenium $\left(\mathrm{Ru} / \mathrm{RuO}_{2}\right)$ as catalyst presented strongly depleted signals in ${ }^{12} \mathrm{CH}_{2} \mathrm{D}_{2}$, which was considered to be caused by quantum tunneling effect (Young et al., 2017). Cao et al. (2019) has further explained this phenomenon using an isotopologuespecific kinetic model, and additional experimental results are required to test this model. Furthermore, lack of data from other FTT reactions with different parameters, limiting this technique as a tool to identify the pathways of natural abiotic $\mathrm{CH}_{4}$ formation, which is widely observed in natural serpentinization systems (Etiope and Whiticar, 2019).

In this study, we will present the clumped isotopic signatures of laboratory produced abiotic $\mathrm{CH}_{4}$ via gaseous FTT reactions, using various experimental parameters and catalysts, such as $\mathrm{Ni}, \mathrm{Fe}, \mathrm{Ru}$ and Co. Both $\Delta^{13} \mathrm{CH}_{3} \mathrm{D}$ and $\Delta^{12} \mathrm{CH}_{2} \mathrm{D}_{2}$ values are analyzed using a 253 Ultra High Resolution Isotope Ratio Mass Spectrometer established in Earth-Life Science Institute (ELSI), Tokyo Institute of Technology, following the similar procedures described in Eldridge et al. (2019). We will discuss the controlling factors of clumped isotopic signatures in laboratory produced abiotic $\mathrm{CH}_{4}$, and try to apply these results in clarifying the producing mechanism of natural abiotic $\mathrm{CH}_{4}$ gases, which might provide additional information to illustrate the early earth environment and life origin, as well as other planet with abiotic $\mathrm{CH}_{4}$ existent.

References: Eldridge et al., 2019, ACS Earth Space Chem.; Cao et al., 2019, Geochim. Cosmochim. Acta.; Etiope and Whiticar, 2019, Applied Geochemistry; Stolper et al., 2014, Geochim. Cosmochim. Acta.; Wang et al., 2018, Geochim. Cosmochim. Acta.; Young et al., 2017, Geochim. Cosmochim. Acta. 